\title{
Effects of Acute Oral Exposure to Acrylamide on Histological Structures of the Stomach in Wistar Rats
}

\author{
Efectos de la Exposición Oral Aguda a la Acrilamida sobre \\ las Estructuras Histológicas del Estómago en Ratas Wistar
}

Sabo, I. J. R. ${ }^{\text {; }}$ Tanja Z. Lakic ${ }^{2,3}$; Ivan D. Capo ${ }^{1}$; Bojana M. Andrejic-Visnjic ${ }^{1}$; Milica Matavulj ${ }^{4}$ Matilda A. Djolai ${ }^{1,2}$

SABO, I. J. R. ; LAKIC, T. Z.; CAPO, I. D.; ANDREJIC-VISNJIC, B. M.; MATAVULJ, M. \& DJOLAI, M. A. Effects of acute oral exposure to acrylamide on histological structures of the stomach in Wistar rats. Int. J. Morphol., 39(4):963-968, 2021.

SUMMARY: Acrylamide is a toxic chemical substance with wide implementation in chemical industry. In 2002 the presence of acrylamide was discovered in foods rich in starch which are prepared at high temperatures. The aim of this study was to investigate the histopathological changes in the gastric tissue in Wistar rats induced with injection of oral acrylamide. The research was carried out 6 groups of 5 animals (Wistar rats), two control groups and four experimental groups. Histological changes in the stomach tissue of Wistar rats are seen as a direct slight damage of the surface epithelium, accompanynig inflammatory reaction and renewal of the epithelium. Examined inflammatory and degenerative parameters show a positive correlation with respect to dose and time of exposition to acrylamide. Knowing the mechanism of action of these toxic substances, allows to apply adequate prevention in nutrition and make an appropriate choice of therapeutic methods.

KEY WORDS: Acrylamide; Food; Stomach; Wistar Rat; Toxicity.

\section{INTRODUCTION}

The first knowledge about acrylamide comes from Moure in 1893, when he produced it in Germany. Since 1954, it is in commercial use in the chemical industry (Aguilar \& San Román, 2019). In 2002, the accidental discovery of certain amounts of acrylamide are found in starch-rich foods such as: French fries, chips, bread, biscuits, as well as, in foods prepared at very high temperatures by baking and frying (Dutra Caldas \& Oliveira Jardim, 2012). The harmful effects of acrylamide are numerous: it causes axon damage (Ewaleifoh et al., 2012), it is classified as proven carcinogen in experimental animals (Sen et al., 2012), it leads to pathological embryogenesis (Marchetti et al., 2009) and reduction in the body weight of newborns (Takahashi et al., 2008). There are just few proven effects of acrylamide on gastric tissue. Cases of accidental oral poisoning with large amounts of acrylamide have been reported, when one of the most visible effects was marked damage gastrointestinal mucosa with extensive bleeding (Sadek et al., 2012). The specific way of life nowadays with frequent use of "fast food", which is rich in acrylamide, represents great risk. The aim of the study was to determine whether acute acrylamide treatment causes qualitative and quantitative changes in the histological structure of the stomach in Wistar rats.

\section{MATERIAL AND METHOD}

Acrylamide Preparation. The experimental study has been applied a solution of acrylamide in distilled water (99\% pure, Sigma Chemical Co., St. Louis, MO, USA). The preparation was administered in a dose of $25 \mathrm{mg} / \mathrm{kg}$ and 50 $\mathrm{mg} / \mathrm{kg}$ of animal body weight.

Experimental Animals. The experiment, which was performed at the Department of Biology and Ecology of the Faculty of Science in Novi Sad, included 30 male Wistar rats. The study was carried out with the approval of the Ethics Committee to safeguard the welfare of experimental animals, University of Novi Sad (number I-2011-03), as well as

\footnotetext{
${ }^{1}$ Department of Histology and Embryology, Faculty of Medicine, University of Novi Sad, Hajduk Veljkova 3, Novi Sad, Serbia.

${ }^{2}$ Clinical Center of Vojvodina, Center for pathology and histology, Hajduk Veljkova 1-9, Novi Sad, Serbia.

${ }^{3}$ Department of Pathology, Faculty of Medicine, University of Novi Sad, Hajduk Veljkova 3, Novi Sad, Serbia.

${ }^{4}$ Department of Biology and Ecology, Faculty of Sciences, University of Novi Sad, Trg Dositeja Obradovica 2, Novi Sad, Serbia.
} 
respecting the recommendations of the NIH (National Institutes of Health, USA) "Guide for the Care and Use of Laboratory Animals". The animals were separated from the mother on the 22nd day after birth, measured and equalized in body weight. The individuals were divided into six groups, two control (treated with distilled water in the amount of 50 $\mu \mathrm{l}$ for 24 and $72 \mathrm{~h}$ ) and four experimental groups (treated with acrylamide dose of 25 and $50 \mathrm{mg} / \mathrm{kg}$ body weight for 24 and 72h) with five individuals in each group. During the experiment, the individuals were kept in plastic cages, under controlled conditions, for $12 \mathrm{~h}$ of light, $12 \mathrm{~h}$ of darkness, room temperature $22 \pm 2{ }^{\circ} \mathrm{C}$. Palletized food and water were available to the animals ad libitum. In all study groups, the solutions were administered orally, via a one-day application in a total volume of $50 \mu \mathrm{l}$, on the day of application at 8 and $30 \mathrm{~h}$ in the morning. On the day of sacrifice, neither distilled water nor acrylamide solution was administered to the animals. The animals were killed at 9:00 a.m., after diethyl ether vapor anesthesia was administered.

Sampling and histological processing of materials. After killing the animals, all samples were fixed in $10 \%$ formalin, $\mathrm{pH}$ 7.2. After fixation, three sections were taken from the stomachs of all examined groups, so that all three anatomical and histological regions were included: I segment-cardia, II segment-corpus, III segment-pylorus. After fixation, which lasted $24 \mathrm{~h}$, the sections were first kept in $70 \%$ ethyl alcohol for 32 days at $4{ }^{\circ} \mathrm{C}$, then $24 \mathrm{~h}$ in $95 \%$ and $23 \mathrm{~h}$ in $100 \%$ ethyl alcohol. After the blocks were formed, all sections were cut with a Reichert microtome into $5 \mathrm{~mm}$ thick sections. The sections were then stained with standard hematoxylin and eosin staining. Standard histochemical staining with the PAS-AB method was used to visualize intracytoplasmic mucins. After laboratory processing of the material, qualitative and quantitative analysis of samples was performed. Quantification of the given parameters was done: by semi quantitative measurements and quantitative stereological measurements. By qualitative, histological analysis, all samples were examined under a BIO OPTICAITALY light microscope, using magnifications of 4, 10, 20 and 40x and 10x magnification of the lens and analyzed and sought changes in histological parameters "under eye control". Photomicrographs were taken using a Leica DM 2000 LED microscope and a Leica DFC 420 camera.

Semi quantitative analysis. Semi quantitative measurements were used to analyze: mucin type, presence and density of lymphocytes and granulocytes in the gastric mucosa. Semi quantitative assessment of mucin type: 0present PAS positivity; 1-present AB positivity in 0-33\% of preparation; 2-present $\mathrm{AB}$ positivity in 34-66\% of preparation; 3-present AB positivity in 67-100\% of preparation. Semi quantitative assessment of the presence and density of lymphocytes/granulocytes in the gastric mucosa: 0-Absence of lymphocytes/granulocytes in the gastric mucosa; 1-presence of lymphocytes/granulocytes in the lamina propria of the gastric mucosa in the form of a mild infiltrate; 2-presence of lymphocytes/granulocytes in the lamina propria gastric mucosa in the form of a mediumdense infiltrate; 3-presence of lymphocytes in the lamina propria of the gastric mucosa in the form of a dense infiltrate/ presence of granulocytes in the glands.

Stereological Analysis. Stereological measurements were performed using a multi-purpose network Weibel test system M42 built into the ocular of the microscope. The stereological quantities that were determined were the volume density of individual phases of gastric tissue. Appropriate magnification (10x ocular and 40x lens) was selected and then analysis was performed on six visual fields, on two non-adjacent histological sections. The first field on the cut was chosen by the method of random selection, and the adjacent five fields, respecting the principles of orientation in stereology towards free lines. The obtained values are then included in the formula: $\mathrm{Vdf}=\mathrm{Pf} / \mathrm{Pt}$ for calculating the volume density (Vdf-phases volume density, Pf-number of phases points, Pt-number of test system points) .

Statistical data processing. Statistical data processing was performed using IBM SPSS Statistics 21. The mean values, standard deviation (standard error SE), statistical significance of the obtained parameters (T test) and Spearman's correlation of all quantitative parameters were calculated. Given the sample size and distribution of values within groups, nonparametric tests were used to assess differences between groups: the Mann-Whitney $\mathrm{U}$ test to compare the two groups and the Kruskal-Wallis test to compare the results of three or more groups.

\section{RESULTS}

Semi quantitative histological analysis. Experimental groups treated with acrylamide in all doses, as well as in all time periods show $\mathrm{AB}$ positivity (the highest results was in AA50/72 group) (Fig. 1). Rare and sporadic lymphocytes were present in the experimental groups AA25/72 and AA50/ 24. Granulocytes in the control groups and experimental group AA25/24 are present in the lamina propria and rated 1 , while in the experimental groups AA25/72, AA50/24 and AA50/72 the semi quantitative assessment of the presence of granulocytes in the lamina propria increases and ranges from 1,8 to 2 . Statistical analysis of semi quantitatively obtained parameters and comparison by individual groups did not show a statistically significant difference. 

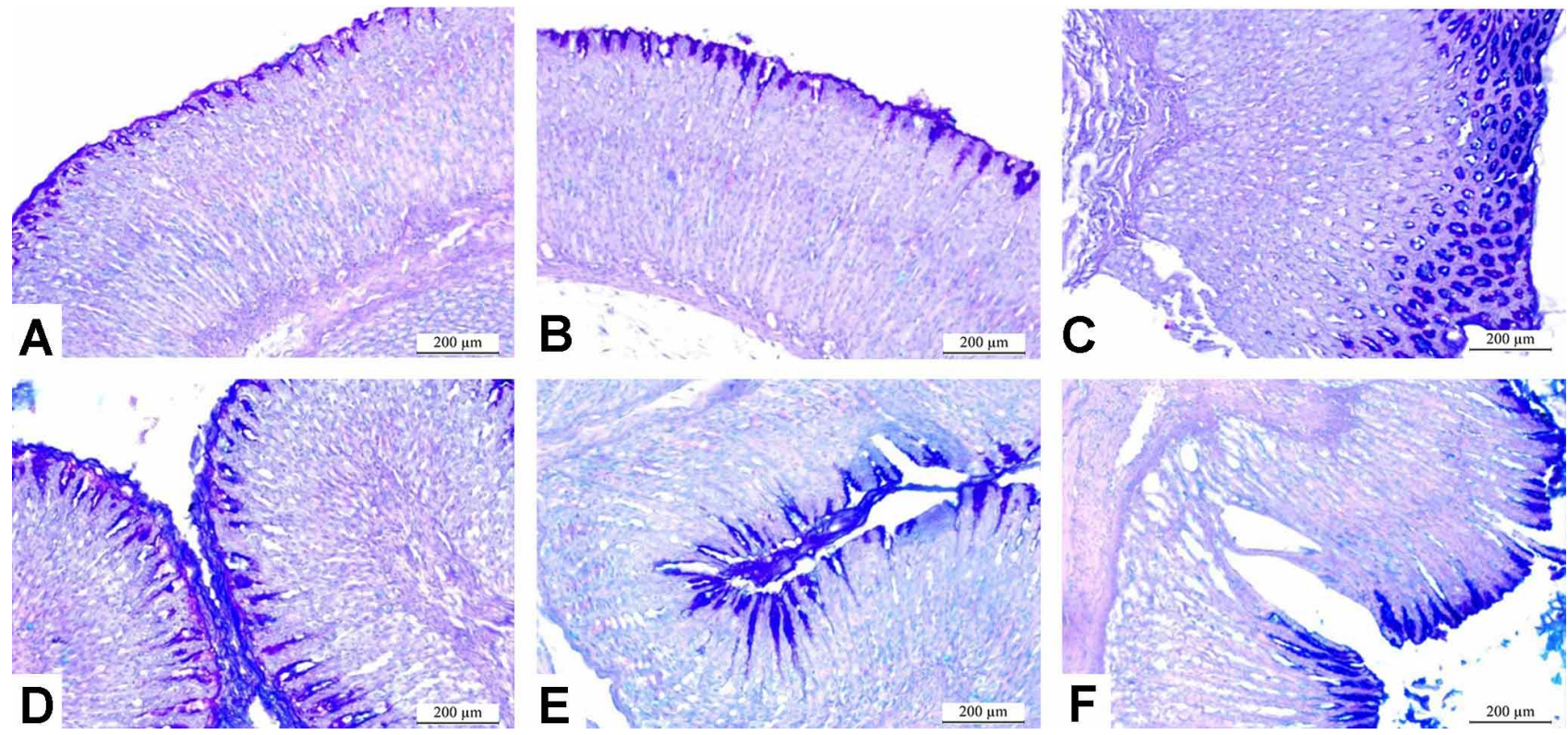

Fig. 1. PAS-AB histochemical staining. A: K24-control group killed after 24 hours. B: K72-control group killed after 72 hours. C: AA25/ 24- experimental group exposed to acrylamide in dose of $25 \mathrm{mg} / \mathrm{kg}$ for 24 hours. D: AA25/72- experimental group exposed to acrylamide in dose of $25 \mathrm{mg} / \mathrm{kg}$ for 72 hours. E: AA50/24- experimental group exposed to acrylamide in dose of $50 \mathrm{mg} / \mathrm{kg}$ for $24 \mathrm{hours}$. F: AA50/72experimental group exposed to acrylamide in dose of $50 \mathrm{mg} / \mathrm{kg}$ for 72 hours.

Results of stereological measurements. The values of mucosal volume density in the acrylamide-treated groups compared to the values in the control groups show a slight

in the groups treated with acrylamide shows a decrease. In all groups treated with acrylamide, an increase in glandular volume density was observed in comparison to the control increase. The volume density of the superficial epithelium
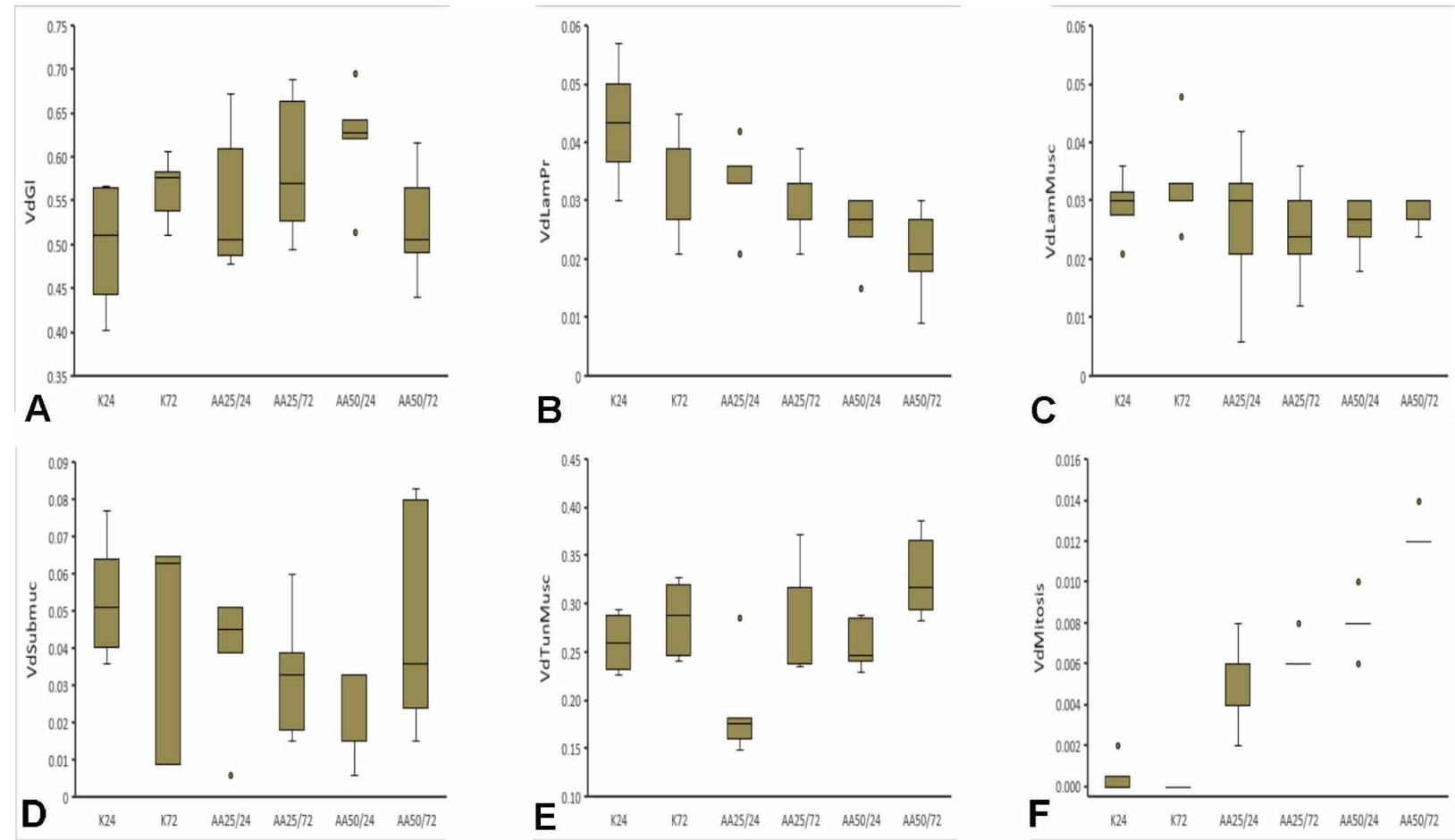

Fig. 2. Volume density values. A: Vd gl-volume density of glands. B: Vd LamPr-volume density of lamina propria. C: Vd Lam Musc-volume density of muscular lamina. D:Vd Submuc-volume density of submucosis. E: Vd Tun Musc-volume density of muscular tunica. F: Vd Mitosis-volume density of cells in mitosis. 
AA 50/24 in relation to the $\mathrm{K} 24$ control group ( $\mathrm{p}=0.05$; $\mathrm{U}$ $=2,000)$. Among the mean values of glandular volume density, there is a statistically significant decrease in the group AA 50/72 in relation to the group AA 50/24 ( $\mathrm{p}=0.028$; $\mathrm{U}=1,000)$. The volume density of lamina propria in the acrylamide-treated groups show a decrease compared to the values in the control groups (Fig. 2), which is statistically significant in the group AA 50/24 in relation to K24 ( $\mathrm{p}=$ $0.025 ; \mathrm{U}=1.000$ ). There is a decrease in the volume density of the muscular lamina in the groups treated with acrylamide. Submucosal volume density values in the acrylamide-treated groups show a decrease. Among the mean values of the volume density of the submucosa, a statistically significant decrease was found in the experimental group AA 50/24 in relation to the control group K24 ( $\mathrm{p}=0.014 ; \mathrm{U}=1,000)$. A statistically significant difference in the volume density of the muscular tunica was registered between groups AA25/ 24 and AA 25/72 ( $\mathrm{p}=0.047 ; \mathrm{U}=3,000)$, as well as between groups AA 50/24 and AA 50/72 ( $\mathrm{p}=0.028 ; \mathrm{U}=2,000)$, associated with a longer period of exposure to acrylamide. The volume density of mitosis (Fig. 3) shows a statistically significant increase between the following groups: K24 and AA 25/24 ( $\mathrm{p}=0.017 ; \mathrm{U}=0.500), \mathrm{K} 24$ and AA 50/24 ( $\mathrm{p}=$ $0.011 ; \mathrm{U}=0.000), \mathrm{K} 72$ and $\mathrm{AA} 25 / 72 \mathrm{p}=0.005 ; \mathrm{U}=0.000)$, $\mathrm{K} 72$ and AA50 / $72(\mathrm{p}=0.006 ; \mathrm{U}=0.000), \mathrm{AA} 25 / 24$ and AA 50/24 ( $=0.039 ; \mathrm{U}=3,000), \mathrm{AA} 25 / 72$ and AA $50 / 72$ $(\mathrm{p}=0.006 ; \mathrm{U}=0.000)$, AA 50/24 and AA 50/72 ( $=0.010$; $\mathrm{U}=0.500$ ), increasing with the dose and time of exposure to acrylamide.

Correlations. Statistically significant correlations between examined parameters have been noted (Tables I and II).
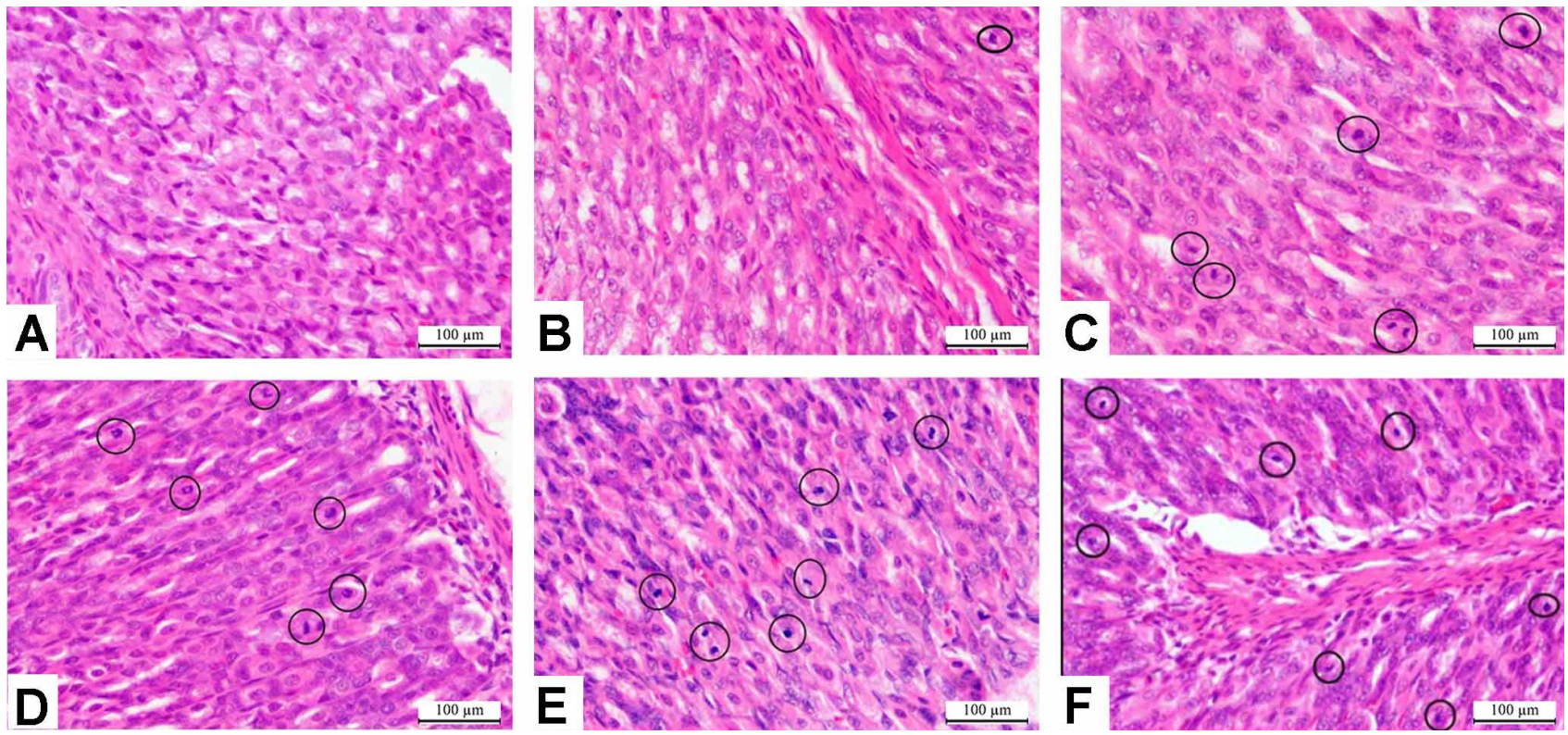

Fig. 3. Cells in mitosis, mucosa of stomach wall, HE, 200x. A: K24 B: K72C: AA25/24 D: AA25/72 E: AA50/24 F: AA50/72.

Table I. Correlations between the parameters obtained by semiquantitative analysis and the volume density of cells in mitosis and parts of the gastric mucosa.

\begin{tabular}{cccccccccc}
\hline & VdMitosis & VdTunMuc & VdEp & VdGl & VdLamPr & VdLamMusc & PAS-AB & Ly & Gr \\
\hline PAS-AB & $\mathbf{. 5 3 6}$ & -.193 & .021 & -.170 & -.305 & $\mathbf{- . 3 9 1}$ & 1.000 & .273 & $\mathbf{. 4 7 1}$ \\
& $\mathbf{. 0 0 3}$ & .316 & .913 & .377 & .108 & $\mathbf{. 0 3 6} *$ & - & .152 & $\mathbf{. 0 1 0}$ \\
Ly & .096 & -.020 & -.115 & .014 & -.068 & -.277 & .273 & 1.000 & .352 \\
& .620 & .917 & .552 & .944 & .726 & .146 & .152 & - & .061 \\
\multirow{2}{*}{ Gr } & $\mathbf{. 7 4}$ & -.008 & -.169 & .165 & $\mathbf{- . 5 6 4}$ & -.110 & $\mathbf{. 4 7 1}$ & .352 & 1.000 \\
& $\mathbf{. 0 0 0} *$ & .966 & .380 & .392 & $\mathbf{. 0 0 1} *$ & .571 & $\mathbf{. 0 1 0}$ & .061 & - \\
\hline
\end{tabular}

*-p-statistical significance between listed parameters. PAS-AB-value of semi quantitative measurement of histological staining of PAS-AB. Ly-value of semi quantitative measurement of lymphocytes in lamina propria mucosis. Gr- value of semi quantitative measurement of granulocytes in lamina propria mucosis. Vd Mitosis-volume density of cells in mitosis. Vd TunMuc-volume density of mucosis. Vd Ep-volume density of superficial epithelium. VdGlvolume density of glands. Vd LamPr-volume density of lamina propria. Vd LamMusc-volume density of muscular lamina 
Table II. Correlations between parameter values obtained by stereological measurements.

\begin{tabular}{lccllc}
\hline & $\begin{array}{l}\text { Vd } \\
\text { TunMuc }\end{array}$ & $\begin{array}{l}\text { Vd } \\
\text { Ep }\end{array}$ & $\begin{array}{l}\text { Vd } \\
\text { Gl }\end{array}$ & $\begin{array}{l}\text { Vd } \\
\text { LamPr }\end{array}$ & $\begin{array}{l}\text { Vd } \\
\text { LamMusc }\end{array}$ \\
\hline Vd & 1.000 & -.054 & $\mathbf{. 9 1 4}$ & -.212 & .236 \\
TunMuc & - & .782 & $\mathbf{. 0 0 0 *}$ & .270 & .217 \\
Vd Ep & -.054 & 1.000 & -.277 & -.057 & .107 \\
& .782 & - & .146 & .768 & .579 \\
Vd Gl & $\mathbf{. 9 1 4}$ & -.277 & 1.000 & -.292 & .112 \\
& $\mathbf{. 0 0 0 *}$ & .146 & - & .124 & .562 \\
Vd LamPr & -.212 & -.057 & -.292 & 1.000 & -.004 \\
& .270 & .768 & .124 & - & .982 \\
Vd & .236 & .107 & .112 & -.004 & 1.000 \\
LamMusc & .217 & .579 & .562 & .982 & - \\
Vd & -.352 & -.033 & $\mathbf{- . 4 1 3}$ & .161 & .158 \\
Submuc & .061 & .865 & $\mathbf{. 0 2 6} *$ & .404 & .412 \\
Vd & $\mathbf{. 5 8 7}$ & -.125 & $\mathbf{- . 4 3 2}$ & -.108 & -.049 \\
TunMusc & $\mathbf{. 0 0 1 *}$ & .519 & $\mathbf{. 0 1 9 *}$ & .577 & .801 \\
Vd Mitosis & .086 & .063 & .174 & $\mathbf{- . 6 7 4}$ & -.108 \\
& .657 & .746 & .366 & $\mathbf{. 0 0 0 *}$ & .576 \\
\hline
\end{tabular}

*-p-statistical significance between listed parameters. Vd TunMuc- volume density of mucosis. Vd Ep- volume density of superfitial epithelium. Vd Gl- volume density of glands. Vd LamPr- volume density of lamina propria. VdLamMusc- volume density of muscular lamina. Vd Submuc- volume density of submucosis. Vd TunMusc- volume density of muscular tunica. Vd Mit- volume density of cells in mitosis.

\section{DISCUSSION}

A modern, fast-paced lifestyle with inadequate care for nutrition affects the health of the human digestive system. It is not uncommon for regular meals to be replaced by dry and fast food. In addition, large amounts of coffee are consumed, with the increasingly popular use of instant coffee (Tareke et al., 2000). So far, the effects of acrylamide on the digestive system, especially the stomach, has been insufficiently investigated and tested (Mottram \& Friedman, 2008). Histological analysis in our study provided a better, more comprehensive insight into changes in gastric tissue. We noted increase of volume density of the gastric mucosa what correlates with the research of Dobrowolski et al. (2012). Altinoz et al. (2015) examined the effect of acrylamide on the small and large intestine of rats and found damage to the superficial epithelium, which confirms our result of reduced volume density of the superficial epithelium. Research conducted in 2012 shows that the action of acrylamide on the intestinal mucosa also leads to damage to the superficial epithelium (Dobrowolski et al.). Glandular volume density in our sample shows an increase in acrylamide-treated groups (increasing with dose and exposure time) confirming the results of the similar studies (Mansour et al., 2008; Dobrowolski et al.). The inflammatory response to acrylamide were confirmed sporadically (Nagi et al., 2014; Maronpot et al., 2015). A study conducted on Wistar rats at the University of Novi Sad, which examined the effect of acrylamide on heart muscle, reported an increase in both cardiomyocyte surface density and an increase in interstitial volume density in treated animals (Injac, 2012). Mansour et al. present the results according to which the muscular layer of the gastric wall is rich in the present inflammatory cellular infiltrate, which may be a contributing factor in increasing the volume of the muscular compartment of the wall. However, the data of the study, Dobrolowski et al., which examined the changes in the small intestine tissue under the action of acrylamide, indicate that there is a reduction in the muscle layer, which is again in contradiction with the results of our study (FurmagaJab?on'ska et al., 2012). The thickening of the muscular layer could be the cause of the appearance of stomach pain and at the same time a contributing factor to the appearance of discomfort on the part of the digestive tract. We determined the type of mucin in gastric epithelial cells. Control groups show the presence of neutral mucins, while in all experimental groups the presence of acidic mucins were confirmed. The increase in the presence of acidic mucins in superficial epithelial cells is a sign of insufficient maturity of mucus cells (Suzuky etal., 1981). The existence of an area of immature mucosa is one of the risks that increase the possibility of cancer in that region (Tsiftsis et al., 1980). The volume density of mitosis in the gastric mucosa shows the reaction of the mucosa to the damage in order to maintain homeostasis and restore the damaged mucosa. A positive correlation was found between the values of mitotic volume density and PAS-AB positivity, as well as the presence of granulocytes in the mucosa. This correlation speaks in favor of the appearance of damaged mucosa accompanied by inflammatory reaction, as well as the self-renew the damaged mucosa. Raju et al. (2011) conducted a study on F344 rats following histopathological changes in the intestinal mucosa, where the results indicate that there is no statistically significant increase in proliferation. A study conducted in 2012 at Indiana University (Indianapolis), where male F344 rats were exposed to oral doses of $15 \mathrm{mg} / \mathrm{kg}$ for 14 days, showed tissue proliferation, but in other organs: liver, thyroid and adrenal glands (Klaunig et al., 2008).

\section{CONCLUSION}

Acute treatment with acrylamide in the stomach structures of Wistar rats caused mild direct damage of the superficial epithelium accompanying acute inflammatory reaction with renewal of the epithelium. The effect of acutely administered acrylamide on the stomach of Wistar rats, shows a positive correlation with dose and length of exposure to acrylamide. 
SABO, I. J. R. ; LAKIC, T. Z.; CAPO, I. D.; ANDREJICVISNJIC, B. M.; MATAVULJ, M. \& DJOLAI, M. A. Effects of acute oral exposure to acrylamide on histological structures of the stomach in Wistar rats. Int. J. Morphol., 39(4):963-968, 2021.

RESUMEN: La acrilamida es una sustancia química tóxica con amplia aplicación en la industria química. En el año 2002 se determinó la presencia de acrilamida en alimentos ricos en almidón preparados a altas temperaturas. El objetivo de este estudio fue investigar los cambios histopatológicos en el tejido gástrico en ratas Wistar inducidos con inyección de acrilamida oral. La investigación se llevó a cabo en 6 grupos de 5 animales, dos grupos control y cuatro grupos experimentales. Los cambios histológicos en el tejido del estómago de las ratas Wistar se ven como un ligero daño directo del epitelio superficial, que acompaña a la reacción inflamatoria y la renovación del epitelio. Los parámetros inflamatorios y degenerativos examinados muestran una correlación positiva con respecto a la dosis y el tiempo de exposición a la acrilamida. El conocimiento del mecanismo de acción de estas sustancias tóxicas permite aplicar una prevención adecuada en nutrición y hacer una elección oportuna de los métodos terapéuticos.

PALABRAS CLAVE: Acrilamida; Comida; Estómago; Rata Wistar; Toxicidad.

\section{REFERENCES}

Aguilar, M. R. \& San Román, J. Smart Polymers and Their Applications. 2nd ed. Oxford, Woodhead Publishing, 2019.

Altinoz, E.; Turkoz, Y. \& Vardi, N. The protective effect of N-acetylcysteine against acrylamide toxicity in liver and small and large intestine tissues. Bratisl. Lek. Listy., 116(4):252-8, 2015.

Dobrowolski, P.; Huet, P.; Karlsson, P.; Eriksson, S.; Tomaszewska, E.; Gawron, A. \& Pierzynowski, S. G. Potato fiber protects the small intestinal wall against the toxic influence of acrylamide. Nutrition, 28(4):428-35, 2012

Dutra Caldas, E. \& Oliveira Jardim, A. N. Exposure to toxic chemicals in the diet: is the Brazilian population at risk? J. Expo. Sci. Environ. Epidemiol., 22(1):1-15, 2012.

Ewaleifoh, O.; Trinh, M.; Griffin, J. W. \& Nguyen, T. A novel system to accelerate the progression of nerve degeneration in transgenic mouse models of neuropathies. Exp. Neurol., 237(1):153-9, 2012.

Furmaga-Jab?on'ska, W.; Jab?on'ski, M. \& Pluta, R. A new polemic to acrylamide toxicity. Nutrition, 28(4):426-7, 2012.

Injac, D. Efekat Subhronicnog Tretmana Akrilamidom Na Strukturu Miokarda. Master Thesis. Novi Sad, Univerzitet u Novom Sadu, Prirodno-Matematicki Fakultet, 2012.

Klaunig, J. E. Acrylamide carcinogenicity. J. Agric. Food Chem., 56(15):5984-8, 2008

Mansour, M. K.; Ibrahim, E. M.; El-Kholy, M. M. \& El-Madawy, S. A. Antioxidant and histopathological effect of catechin and neem leaves extract in acrylamide toxicity of rats. Egypt. J. Comp. Path. Clin. Pathol., 21(1):290-313, 2008.

Marchetti, F.; Bishop, J.; Lowe, X. \& Wyrobek, A. J. Chromosomal mosaicism in mouse two-cell embryos after paternal exposure to acrylamide. Toxicol. Sci., 107(1):194-205, 2009.

Maronpot, R. R.; Thoolen, R. J. M. M. \& Hansen, B. Two-year carcinogenicity study of acrylamide in Wistar Han rats with in utero exposure. Experim. Toxicol. Pathol., 67(2):189-95, 2015.
Mottram, D. S. \& Friedman, M. Symposium on the chemistry and toxicology of acrylamide. J. Agric. Food Chem., 56(15):5983, 2008.

Nagi, H. M.; Amin, W. S. M. \& Zaki, S. A. The Potential Effect of Fruits and Vegetables on Liver Functions and Liver Alterations Induced by Acrylamide in Mice. 3rd International Conference on Nutrition and Food Sciences - IPCBEE 71(2014):71:5-9, 2014.

Raju, J.; Sondagar, C.; Roberts, J.; Aziz, S. A.; Caldwell, D.; Vavasour, E. \& Mehta, R. Dietary acrylamide does not increase colon aberrant crypt foci formation in male F344 rats. Food Chem. Toxicol., 49(6):1373-80, 2011.

Sadek, K. M. Antioxidant and immunostimulant effect of carica papaya linn. Aqueous extract in acrylamide intoxicated rats. Acta Inform. Med., 20(3):180-5, 2012.

Sen, A.; Ozgun, O.; Arinç, E. \& Arslan, S. Diverse action of acrylamide on cytochrome $\mathrm{P} 450$ and glutathione S-transferase isozyme activities, mRNA levels and protein levels in human hepatocarcinoma cells. Cell Biol. Toxicol., 28(3):175-86, 2012.

Suzuky, I.; Taguch, I.; Kojima, A.; Matsuyama, M. \& Nishizuka, Y. Fine structure of giant hypertrophic gastritis developed in thymectomized mice. Lab. Invest., 45(3):209-17, 1981.

Takahashi, M.; Shibutani, M.; Inoue, K.; Fujimoto, H.; Hirose, M. \& Nishikawa, A. Pathological assessment of the nervous and male reproductive systems of rat offspring exposed maternally to acrylamide during the gestation and lactation periods - a preliminary study. Toxicol. Sci., 33(1):11-24, 2008.

Tareke, E.; Rydberg, P.; Karlsson, P.; Eriksson, S. \& Törnqvist, M. Acrylamide: a cooking carcinogen? Chem. Res. Toxicol., 13(6):51722, 2000.

Tsiftsis, D.; Jass, J. R.; Filipe, M. I. \& Wastell, C. Altered patterns of mucin secretion in precancerous lesions induced in the glandular part of the rat stomach by the carcinogen $\mathrm{N}$-methyl-N'-nitro-N-nitrosoguanidine. Invest. Cell. Pathol., 3(4):399-408, 1980.

Corresponding author:

Jelena llic Sabo

HajdukVeljkova 3

21000 Novi Sad

SERBIA

E-mail: jelena.ilic-sabo@mf.uns.ac.rs

ORCID iD: 0000-0002-5003-8512

Received: 06-03-2021

Accepted: 14-05-2021 